\section{Enhancement of Growth and Development of Tomato Seedlings by Extending the Light Period Each Day}

Hiromi Toida, ${ }^{1}$ Katsumi Ohyama, ${ }^{2}$ Yoshitaka Omura, ${ }^{3}$ and Toyoki Kozai ${ }^{4}$ Faculty of Horticulture, Chiba University, Matsudo, Chiba 271-8510, Japan

Additional index words. artificial lighting, electrical energy consumption, Lycopersicon esculentum, nonperiodic alternation, photomorphogenesis, photoperiodism, phytochrome

Abstract. The light and dark periods can be easily controlled by the use of artificial lighting. To understand the effects of alternation of light and dark periods on plant growth and development, we studied the growth and development of tomato ('Momotaro') seedlings under nonperiodic alternation of light and dark periods. Tomato seedlings grown under two nonperiodic alternation treatments of NF (NF-1 and NF-2) were compared with seedlings grown under a periodic alternation treatment ( $P$ treatment) with 12-hour light and dark periods. In all treatments, photosynthetic photon flux (PPF) during the light period was maintained at $280 \mu \mathrm{mol} \cdot \mathrm{m}^{-2} \cdot \mathrm{s}^{-1}$; the sum of each light period and the following dark period was 24 hours; and each of the integrated light and dark periods was 132 hours during 11 days of the experiment. In NF-1, the initial light and dark periods were 7 and 17 hours, respectively, and the light period was extended 1 hour per day, while in NF-2, they were initially 17 and 7 hours, respectively, and the light period was shortened 1 hour per day. At the end of the experiment, dry weight per seedling was greater and flower-bud initiation of the first flower truss was earlier in NF-1 than in NF-2 and P, even though the integrated $P P F$ during the experiment was the same in all treatments. These results demonstrate that growth and development of tomato seedlings can be enhanced without any increase in electric energy consumption for lighting by gradually extending the light period or shortening the dark period.

Recently, closed plant production systems with artificial lighting have come to the forefront, and many studies have been conducted about lighting (e.g., Fang and Jao, 2000; Goto, 1997). In Japan, Kozai et al. (2004) developed a prototype of a closed plant production system with artificial lighting for commercial production of high quality transplants, and the system has been commercialized. Artificial lighting in this type of system can be easily controlled to create nonperiodic alternation of light and dark periods, although periodic alternation of light and dark periods, particularly 24 -h periodic alternation, has been generally used in this system. To control plant growth and development, it is important to accumulate the results of a study on the effects of lighting on plant growth and development.

Maximal plant growth, often expressed as dry weight, is generally obtained to result under a 24-h periodic alternation of light and dark periods as compared with plant growth under various alternations, even when those alternations provide the same integrated light period or amount of light energy (e.g., Highkin

Received for publication 16Apr. 2004. Accepted for publication 11 Sept. 2004. We thank Chieri Kubota and Fawzia Afreen for helpful discussions and reviews of this manuscript. The use of trade names in this manuscript is solely to ensure accurate description of experimental conditions. No endorsement or criticism of these products or similar products not mentioned is intended.

${ }^{1}$ Graduate student. Corresponding author; e-mail hiromit@graduate.chiba-u.jp.

${ }^{2}$ Reserch fellow of the Japan Society for the Promotion of Science.

${ }^{3}$ Graduate student.

${ }^{4}$ Professor. and Hanson, 1954). Plant growth and development are generally considered to be greater under periodic alternation of light and dark periods than under nonperiodic alternation of light and dark periods (e.g., Hillman, 1956; Ketellapper, 1960). In general, circadian rhythms in plants have a period of about $24 \mathrm{~h}$, and are synchronized to environmental signals such as alternation of light and dark periods. For example, circadian elongation rhythms in stems have been found in Lycopersicon esculentum (Bertram and Karlsen, 1995; Ibrahim et al., 1981). On the other hand, plants exhibit different growth habits during the light and dark periods, and leaf expansion during the light period (Elliott, 1975, 1979) and stem elongation during dark period (Morgan and Smith, 1979) are known to be controlled by phytochrome. In these earlier studies about the effect of lighting on plants, little attention was given to plant growth and development under nonperiodic alternation of the light and dark periods. Recently, we have studied growth and development of tomato seedlings under nonperiodic alternation of light and dark periods (Toida et al., 2003a, 2003). We have found that in some cases the growth and development of tomato seedlings were better when the alternation of light and dark periods was nonperiodic than when it was periodic. For example, nonperiodic alternation of light and dark periods resulted in longer stem length, greater dry weight or earlier flower-bud initiation. Moreover, tomato seedlings might be enhanced by gradually extending the light period of nonperiodic alternation of light and dark periods, as compared with seedlings (a) P treatment

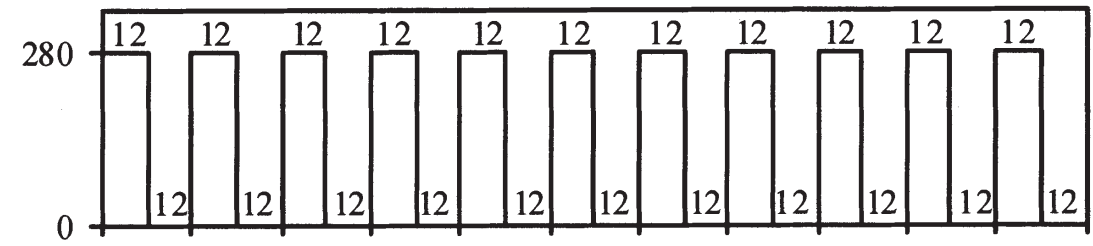

(b) NF-1 treatment

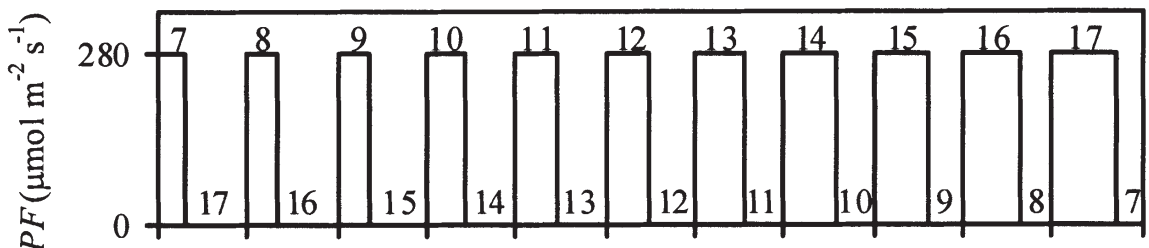

(c) NF-2 treatment

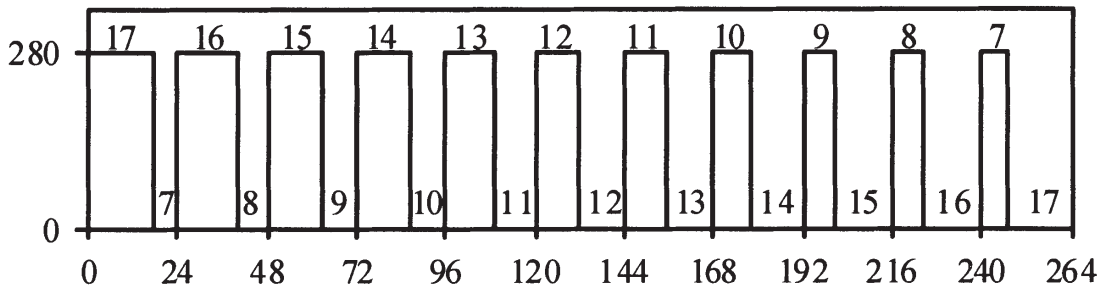

Time after starting the experiment $(\mathrm{h})$

Fig. 1. Time course of light and dark periods in treatments of (a) P (periodic alternation of 12-h light and 12-h dark periods), (b) NF-1 (nonperiodic alternation with extending light period), and (c) NF-2 (nonperiodic alternation with shortening light period). The numbers above and below the square waves express the light and dark periods, respectively. Light-dark period is $24 \mathrm{~h}$ in all treatments. PPF, photosynthetic photon flux. 

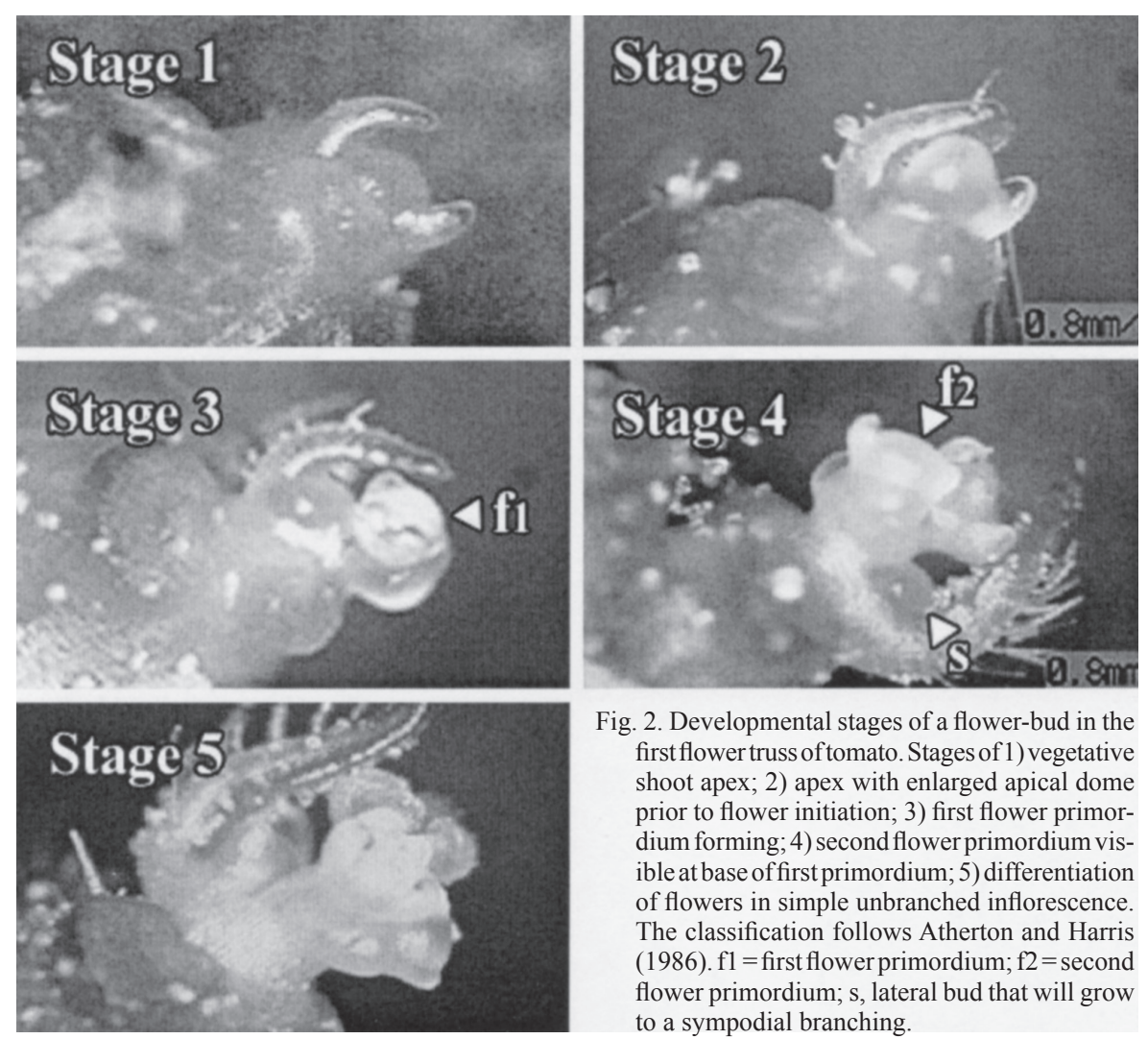

Fig. 2. Developmental stages of a flower-bud in the

under periodic alternation with the same integrated light period. In this paper, growth and development of tomato seedlings grown under nonperiodic alternations in which the light period is gradually extended or gradually shortened were compared with those under periodic alternation of light and dark periods, to verify whether growth and development are enhanced under nonperiodic alternation of light and dark periods.

\section{Materials and methods}

Plant material and growth conditions. One tomato (Lycopersicon esculentum Mill. 'Momotaro') seed was sown in each cell (31 $\mathrm{mm}$ long $\times 31 \mathrm{~mm}$ wide $\times 44 \mathrm{~mm}$ high) of trays each with four cells containing a commercial soil substrate. After sowing, tomato seedlings were grown in the dark for $3 \mathrm{~d}$ and then under 16-h light period and 8-h dark period for the following $3 \mathrm{~d}$. PPF (photosynthetic photon flux) was set at $150 \mu \mathrm{mol} \cdot \mathrm{m}^{-2} \cdot \mathrm{s}^{-1}$ during the light period. Lighting was provided by highfrequency fluorescent tubes (FHF32EX-W, Matsushita Electric Industrial Co., Ltd., Osaka, Japan). Air temperature was set at $28^{\circ} \mathrm{C}$ for $16 \mathrm{~h}$ and $18{ }^{\circ} \mathrm{C}$ for $8 \mathrm{~h}$ each day.

Experimental treatments and conditions. Tomato seedlings with expanded cotyledons grown under two treatments (NF-1 and NF-2, Fig. 1) of nonperiodic alternation of light and dark periods were compared with seedlings grown under a treatment of periodic alternation (P treatment: constant 12-h light and 12-h dark periods). The experiment was conducted for $11 \mathrm{~d}$ in a growth chamber (3HN-MLA; Koito Industries, Ltd., Kanagawa, Japan). At this stage seedlings had three to five true test.

y Observation not performed. first flower truss of tomato. Stages of 1) vegetative shoot apex; 2) apex with enlarged apical dome prior to flower initiation; 3) first flower primordium forming; 4) second flower primordium visible at base of first primordium; 5) differentiation of flowers in simple unbranched inflorescence. The classification follows Atherton and Harris (1986). $\mathrm{f} 1$ = first flower primordium; $\mathrm{f} 2$ = second flower primordium; s, lateral bud that will grow to a sympodial branching.

plied with water on days 1,7 , and 11 and with nutrient solution (Hi-spirit, Taiyo-Kogyo Co., Tokyo, Japan, N, $120 \mathrm{mg} \cdot \mathrm{L}^{-1}, \mathrm{P}, 30 \mathrm{mg} \cdot \mathrm{L}^{-1}, \mathrm{~K}$, $\left.160 \mathrm{mg} \cdot \mathrm{L}^{-1}\right)$ on days 4 and 9 .

After the 11-d experiment, the tomato seedlings were grown for an additional $6 \mathrm{~d}$ under a periodic alternation of 16-h light and 8-h dark periods. During the 6-d period, air temperature was set at $28^{\circ} \mathrm{C}$ during the light period and 18 ${ }^{\circ} \mathrm{C}$ during the dark period.

Data collection and analysis. Stem length, leaf area including cotyledons and dry weight were measured on days 6 and 11, respectively. Stem elongation rate, relative growth rates based on leaf area $\left(\mathrm{RGR}_{\mathrm{L}}\right)$ and dry weight $\left(\mathrm{RGR}_{\mathrm{DW}}\right)$ were calculated during the first $6 \mathrm{~d}$ and last $5 \mathrm{~d}$ of the experiment, respectively. The developmental stage of a flower-bud for the first flower truss was observed with a digital microscope (VH-5900; Keyence Co., Osaka, Japan) on day 11. Details of each developmental stage of a flower bud, as defined by Atherton and Harris (1986), are shown in Fig. 2. The number of true leaves preceding the first flower truss differentiation was counted with the digital microscope $6 \mathrm{~d}$ after the end of the experiment.

Twelve seedlings from each treatment were taken for each measurement and observation. The experiment was replicated three times, and was based on a Latin square design. Differences among treatments were tested by a LSD test at $P \leq 0.05$ performed with the GLM procedure of SAS (SAS Institute Inc., Cary, N.C.). For the first flower truss, differences among treatments were tested by the Wilcoxon $t$ test with Bonferroni correction preformed with the NPAR1WAY procedure of SAS. The data used in the statistical analysis were averages of three replicates each with 12 seedlings.

\section{Results and discussion} and the following dark period was $24 \mathrm{~h}$; and the integrated light period was $132 \mathrm{~h}$ for 11 d (264 h). High-frequency fluorescent tubes (FHF16EX-W, Matsushita Electric Industrial Co., Ltd., Osaka, Japan) were used as the light source. $P P F$ was measured on days 1,6 , and 11 , and was maintained at $280 \mu \mathrm{mol} \cdot \mathrm{m}^{-2} \cdot \mathrm{s}^{-1}$ during the experiment. Air temperature and relative humidity were set at $24{ }^{\circ} \mathrm{C}$ and $70 \%$ during the experiment. Subirrigation was ap-
Growth. Stem length was greatest in NF-1, followed by P and NF-2 on day 6, while stem length was not significantly different on day 11 (Table 1). The stem elongation rate in NF-1 was greater than that in $\mathrm{P}$ and NF-2 during the first $6 \mathrm{~d}$, while the elongation rate in NF-1 was lower than that in $\mathrm{P}$ and NF-2 during the last 5 $\mathrm{d}$ (Table 2). Stem elongation has been reported

Table 1. Growth of tomato seedlings on days 6 and 11, and number of true leaves preceding the first flower truss differentiation (NL) $6 \mathrm{~d}$ after the end of the experiment (Day 17). For details of treatment codes, see Fig. 1. Data are means of three replications each with 12 seedlings.

\begin{tabular}{|c|c|c|c|c|c|}
\hline $\begin{array}{l}\text { Measurement } \\
\text { day }\end{array}$ & $\begin{array}{l}\text { Treatment } \\
\text { code }\end{array}$ & $\begin{array}{l}\text { Stem length } \\
(\mathrm{cm})\end{array}$ & $\begin{array}{l}\text { Leaf area } \\
\qquad\left(\mathrm{cm}^{2}\right)\end{array}$ & $\begin{array}{l}\text { Dry wt } \\
(\mathrm{mg})\end{array}$ & NL \\
\hline \multicolumn{6}{|l|}{ Day 6} \\
\hline & $\mathrm{P}$ & $5.7 b^{z}$ & $10.8 \mathrm{a}$ & $24.4 \mathrm{~b}$ & $---y$ \\
\hline & NF-1 & $6.3 \mathrm{a}$ & $7.8 \mathrm{~b}$ & $17.9 \mathrm{c}$ & --- \\
\hline & NF-2 & $5.4 \mathrm{c}$ & $11.6 \mathrm{a}$ & $27.6 \mathrm{a}$ & --- \\
\hline \multicolumn{6}{|l|}{ Day 11} \\
\hline & $\mathrm{P}$ & 8.9 & $63.7 \mathrm{a}$ & $118.3 \mathrm{~b}$ & --- \\
\hline & NF-1 & 9.0 & $53.4 \mathrm{c}$ & $131.1 \mathrm{a}$ & --- \\
\hline & NF-2 & 8.6 & $57.9 \mathrm{~b}$ & $94.9 \mathrm{c}$ & --- \\
\hline \multicolumn{6}{|l|}{ Day 17} \\
\hline & $\mathrm{P}$ & --- & --- & --- & $9.1 \mathrm{~b}$ \\
\hline & NF-1 & --- & --- & --- & $7.9 \mathrm{c}$ \\
\hline & NF-2 & --- & --- & -- & $9.3 \mathrm{a}$ \\
\hline
\end{tabular}

${ }^{\mathrm{z}}$ Means in each column followed by the same letters are not significantly different at $P \leq 0.05$ by a LSD 
Table 2. Stem elongation rate, specific leaf area (SLA) and relative growth rates based on leaf area (RGR $)$ and dry weight of whole seedling $\left(\mathrm{RGR}_{\mathrm{DW}}\right)$ during the first $6 \mathrm{~d}$ and last $5 \mathrm{~d}$ of the experiment. For details of treatment codes, see Fig. 1.

\begin{tabular}{lccccc}
\hline Day & $\begin{array}{c}\text { Treatment } \\
\text { code }\end{array}$ & $\begin{array}{c}\text { Stem elongation } \\
\text { rate }\left(\mathrm{mm} \cdot \mathrm{d}^{-1}\right)\end{array}$ & $\begin{array}{c}\mathrm{SLA}^{z} \\
\left(\mathrm{~m}^{2} \cdot \mathrm{g}^{-1}\right)\end{array}$ & $\begin{array}{c}\mathrm{RGR}_{\mathrm{LA}}{ }^{\mathrm{y}} \\
\left(\mathrm{d}^{-1}\right)\end{array}$ & $\begin{array}{c}\mathrm{RGR}_{\mathrm{DW}}{ }^{\mathrm{x}} \\
\left(\mathrm{d}^{-1}\right)\end{array}$ \\
\hline First 6 d & $\mathrm{P}$ & 0.45 & 0.61 & 0.41 & 0.32 \\
& $\mathrm{NF}-1$ & 0.55 & 0.62 & 0.36 & 0.27 \\
Last 5 d & $\mathrm{NF}-2$ & 0.41 & 0.59 & 0.43 & 0.35 \\
& $\mathrm{P}$ & 0.64 & 0.71 & 0.34 & 0.32 \\
& $\mathrm{NF}-1$ & 0.54 & 0.54 & 0.37 & 0.40 \\
& $\mathrm{NF}-2$ & 0.66 & 0.84 & 0.31 & 0.25 \\
\hline
\end{tabular}

${ }^{2} \mathrm{SLA}=A / W_{\mathrm{A}}$, where $A$ and $W_{\mathrm{A}}$ denote the leaf area and the dry leaf weight, respectively.

${ }^{\mathrm{y}} \mathrm{RGR}_{\mathrm{LA}}=\left\{\ln \left(A_{2}\right)-\ln \left(A_{1}\right)\right\} /\left(T_{2}-T_{1}\right)$, where $A_{1}$ and $A_{2}$ denote the leaf area on days $T_{1}$ and $T_{2}$, respectively. $T_{1}$ is day 0 and $T$ is day 6 during the first $6 \mathrm{~d}$, and $T$ is day 6 and $T$ is day 11 during the last $5 \mathrm{~d}$.

${ }^{\times} \mathrm{RGR}_{\mathrm{DW}}=\left\{\ln \left(W_{2}\right)-\ln \left(W_{1}\right)\right\} /\left(T_{2}-T_{1}\right)$, where $W_{1}$ and $W_{2}$ denote the dry weights on days $T_{1}$ and $T_{2}$, respectively. $T_{1}$ is day 0 and $T_{2}$ is day 6 during the first $6 \mathrm{~d}$, and $T_{1}$ is day 6 and $T_{2}$ is day 11 during the last $5 \mathrm{~d}$.

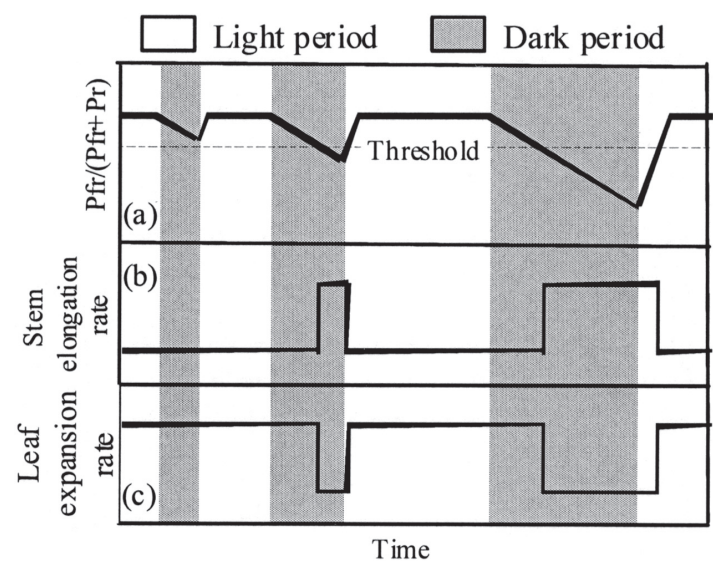
to be controlled by the phytochrome system(Elliott, 1979; Hopkins, 1995; Morgan and Smith, 1979; Oleze-Karow and Mohr, 1989; Salisbury and Ross, 1992). Elliott (1979) suggested that stem elongation of pea (Pisum sativum L.) seedlings was less during the light period than during the dark period, and the elongation was controlled by phytochrome. Oelze-Karow and Mohr (1989) found that hypocotyl elongation in mustard (Sinapis alba L.) seedlings was controlled by the $\mathrm{Pfr} /(\mathrm{Pfr}+\mathrm{Pr})$ ratio, where Pfr and Pr are the contents of the far-red lightabsorbing form and red light absorbing form of phytochrome, respectively. Elongation was found to be all-or-none reaction depending on whether the ratio was above or below a certain threshold. Morgan and Smith (1979) found that the $\mathrm{Pfr} /(\mathrm{Pfr}+\mathrm{Pr})$ ratio had an affect on the stem elongation rate of species that normally grow in a more sunlit environment. Based on these reports, a hypothesis to interpret the result of the experiment on stem elongation and leaf expansion rates was developed (Fig. 3). This hypothesis can be applied to stem elongation and leaf expansion rates under not only periodic but also nonperiodic alternation of light and dark periods. Phytochrome is in its inactive form $(\mathrm{Pr})$ in the dark and is reversibly converted to its active form (Pfr) by light (Mancinelli,

Table 3. Dry leaf weight and leaf-to-whole seedling dry weight ratio on day 11. For details of treatment codes, see Fig. 1.

\begin{tabular}{lcc}
\hline $\begin{array}{l}\text { Treatment } \\
\text { code }\end{array}$ & $\begin{array}{c}\text { Dry leaf } \\
\text { wt }(\mathrm{mg})\end{array}$ & $\begin{array}{c}\text { Leaf/whole seedling } \\
\text { dry wt }\end{array}$ \\
\hline $\mathrm{P}$ & 86.9 & 0.74 \\
$\mathrm{NF}-1$ & 95.3 & 0.73 \\
NF-2 & 69.9 & 0.74 \\
\hline
\end{tabular}

Fig. 3. Schematic diagram showing a hypothesis to interpret the results on stem elongation and leaf expansion rates controlled by the $\mathrm{Pfr} /(\mathrm{Pfr}+\mathrm{Pr})$ ratio through its threshold response (After Elliott, 1975 and 1979; Mohr, 1972; Oelze-Karow and Mohr, 1989). The three lines show the time courses of (a) $\mathrm{Pfr} /(\mathrm{Pfr}+\mathrm{Pr})$ ratio, (b) the stem elongation rate, and (c) the leaf expansion rate. Pfr and Prdenote contents of far-red light- and red light-absorbing forms of phytochrome, respectively.

1994). Therefore, the $\mathrm{Pfr} /(\mathrm{Pfr}+\mathrm{Pr})$ ratio after the start of the dark period would decrease at a constant rate in each dark period (Fig. 3a). The rates

length was not significantly different among the treatments, although the stem lengths differed by $1 \mathrm{~cm}$ between NF-1 and NF-2 on day 6. One possible reason for the absence of significant differences in stem lengths among the treatments was that NF-2 had long dark periods for the last $5 \mathrm{~d}$ of the experiment and the stem elongation in this treatment was enhanced, while in NF-1 it was hardly enhanced for the last $5 \mathrm{~d}$. Another possible reason was that the elongation rate for the last $5 \mathrm{~d}$ was greater than that for the first $6 \mathrm{~d}$.

Leaf area per seedling was greater in $\mathrm{P}$ and NF-2 than in NF-1 on day 6 (Table 1). On day 11 , leaf area was greatest in $\mathrm{P}$, followed by NF-2 and NF-1. In contrast to stem elongation, leaf expansion is enhanced by lighting(Elliott, 1975, 1979). Leaf expansion rate is considered to be enhanced when the $\mathrm{Pfr} /(\mathrm{Pfr}+\mathrm{Pr})$ ratio exceeds the threshold (Mohr, 1972). The low leaf area in NF-1 on day 6 can be explained by the fact that for the first 6 days of the experiment, NF-1 had long dark periods (Fig. 1 and $3)$. On day 11, leaf area, or leaf expansion, in NF-1 was expected to be greatest among the treatments, but, in fact, it was lowest. The result of specific leaf area showed that the leaf in NF-1 was the thickest among the treatments, and $\mathrm{RGR}_{\mathrm{LA}}$ in NF-1 was greatest among the treatments on day 11 (Table 2). These results indicate that leaf area in NF-1 did not expand, but that leaf growth, or leaf thickness, was enhanced. Thus, there is some possibility of controlling leaf expansion and thickness by the phytochrome system.

The stem elongation and leaf expansion mentbecause each treatmenthad the same $P P F$ and same light sources. Thus, the amount of time that the $\mathrm{Pfr} /(\mathrm{Pfr}+\mathrm{Pr})$ ratio exceeded the threshold would be the same regardless of the length of the dark period. When the dark period is short, stem elongation would not occur (Fig. $3 \mathrm{~b}$, left), but when the dark period is longer, stem elongation would be enhanced (Fig. 3b, middle and right). On day 6 , stem length in NF-1 was greatest among the treatments, probably because NF-1 had long dark periods for the first $6 \mathrm{~d}$ of the experiment. On the other hand, stem length in NF-2 was the least among the treatments, probably because NF-2 had short dark periods for the first $6 \mathrm{~d}$. On day 11, stem

Table 4. Developmental stages of a flower-bud in the first truss on day 11. For the developmental stage, see Fig. 4 and for details of treatment codes, see Fig. 1. Data shown for the number of seedlings are the total of three replicate treatments each involving 12 seedlings.

\begin{tabular}{lccc}
\hline Developmental & \multicolumn{3}{c}{ No. of seedlings } \\
\cline { 2 - 4 } stage & $\mathrm{P}$ & NF-1 & NF-2 \\
\hline 1 & $1^{\mathrm{z}}$ & 1 & 0 \\
2 & 19 & 0 & 27 \\
3 & 11 & 12 & 7 \\
4 & 5 & 20 & 1 \\
5 & 0 & 2 & 0 \\
Mean $^{\mathrm{y}}$ & $2.6 \mathrm{~b}^{\mathrm{x}}$ & $3.6 \mathrm{a}$ & $2.3 \mathrm{~b}$ \\
\hline
\end{tabular}

zTotal number of seedlings from three replications.

${ }^{\mathrm{y}}$ Mean $=($ developmental stage $\times$ number of seed lings of the stage)/(total number of seedlings of the treatment)

xThe same letter among the treatments was not significantly different at $P \leq 0.05$ level by the Wilcoxon $t$ test with Bonferroni correction. rates that we observed were interpreted as being under the control of the phytochrome system. Many studies of the phytochrome control mechanism have been conducted under monochromatic light. Under whitelight conditions, both Pr and Pfr are excited, and phytochrome is converted continuously between Pr and Pfr. Although a few studies have examined the conversion between $\mathrm{Pr}$ and Pfr under natural sunlight or fluorescent-light conditions, the mechanism of the conversion is not clear (Taiz and Zeiger, 1991).

Dry weight per whole seedling was greatest in NF-2, followed by P and NF-1 on day 6 . On day 11, dry weight was greatest in NF-1, followed by P and NF-2 (Table 1). On day 6, the dry weight in NF-2 was greatest among the treatments, probably because NF-2 had long light periods for the first 6 days of the experiment. On day 11, dry weight in NF-1 was greatest among the treatments, probably because NF-1 had long light periods for the last $5 \mathrm{~d}$ of the experiment. Tomato seedlings on day 11 grew more than those on day 6 . Therefore, the treatment with long light periods in the latter half resulted in better growth than the treatment with long light periods in the first half, even though the integrated light periods in the two treatments were the same. This suggests that the increasing light period in NF-1 enhanced growth effectively. Another that NF-1 had the greatest leaf growth, which is controlled by the phytochrome system. The leaf-to-whole seedling dry weight ratio was reason for the greatest dry weight in NF-1 was 
almost the same among the treatments, and dry leaf weight accounted for a large portion of the whole seedling weight (Table 3 ). Hence, $\mathrm{RGR}_{\mathrm{DW}}$ and $\mathrm{RGR}_{\mathrm{LA}}$ showed the similar relationship, for example, the high $\mathrm{RGR}_{\mathrm{DW}}$ resulting from the high $\mathrm{RGR}_{\mathrm{LA}}$ in NF-1. Thereby, the dry weight in NF-1 was greatest among the treatments at the end of the experiment because of the greatest leaf weight at that time.

Development. Flower-bud initiation of the first flower truss was more enhanced in NF-1 than in P and NF-2 at the end of the experiment (Fig. 2, Table 4). Tomato is a quantitative short-day plant (Hurd, 1973; Wittwer, 1963). Therefore, the number of true leaves preceding the first flower truss differentiation is affected by the light period. NF-1 provided short days during the first half of the experiment and long days during the latter half of the experiment, while NF-2 provided the opposite progression. The tomato seedlings seemed to be affected by the light period during the first half of the experiment rather than the light period during the last half of the experiment, because the flower-bud initiation of the first flower truss was most enhanced in NF-1. As a result, the number of true leaves preceding the first flower truss differentiation was lowest in NF-1 (Table 1). In contrast to flower-bud initiation in NF1, flower-bud initiation in NF-2 was delayed because of the long days during the first half of the experiment. Early flower-bud initiation such as that in NF-1 may result in earlier harvest of tomato fruits after transplanting.

Growth and development of tomato seedlings and electrical energy consumption for lighting. In this experiment, the light sources were the same in all growth chambers, and the integrated light periods and the number of light periods were the same among the treatments. Thus, the electric energy consumption for lighting was estimated to be the same among the treatments. Two advantages that NF-1 has over P and NF-2 are that it results in a greater dry weight and earlier flower-bud initiation without increasing electric energy consumption for lighting. This would reduce electrical energy consumption for lighting for a given amount of production.

\section{Conclusions}

Tomato seedlings grown under two treatments of nonperiodic alternations with extending or shortening light period (NF-1 and NF-2) were compared with seedlings grown under a periodic alternation treatment $(\mathrm{P})$ with 12-h light and 12-h dark periods. In NF-1, the light period was gradually extended each day, while in NF-2, the light period was gradually shortened. In all treatments, the integrated light period was $132 \mathrm{~h}$ for $11 \mathrm{~d}(264 \mathrm{~h})$ of the experiment. Among the three treatments, NF-1 resulted in the greatest dry weight and earliest flower-bud initiation of the first flower truss. Stem length and leaf expansion seem to be under the control of the phytochrome system. Growth and development of tomato seedlings can be enhanced without any increase in electric energy consumption for lighting by gradually extending the light period.

\section{Literature Cited}

Atherton, J.G. and G.P. Harris. 1986. Flowering, p. 167-200. In: J.G. Atherton and J. Rudich (eds.). The tomato crop. Chapman \& Hall, London.

Bertram, L. and P. Karlsen. 1995. Kinetics and circadian rhythms of stem elongation in greenhouse plants. Acta Hort. 378:56-61.

Elliott, W.M. 1975. Light-controlled leaf expansion in pea grown under different light conditions. Plant Physiol. 55:717-719.

Elliott, W.M. 1979. Control of leaf expansion and stem growth in light-grown pea seedlings by two high irradiance responses. Plant Physiol. 63:833-836.

Fang, W. and R.C. Jao. 2000. A review on artificial lighting on tissue cultures and transplants, $\mathrm{p}$. 108-113. In: C. Kubota and C. Chun (eds.). Transplant production in the 21st century. Kluwer Academic Publishers, Dordrecht.

Goto, E. 1997. Environmental control for plant production in space CELSS, p. 279-296. In: E. Goto, K. Kurata, M. Hayashi, and S. Sase (eds.). Plant production in closed ecosystems. Kluwer Academic Publishers, Dordrecht.

Highkin, H.R. and J.B. Hanson. 1954. Possible interaction between light-dark cycles and endogenous daily rhythms on the growth of tomato plants. Plant Physiol. 29:301-302.
Hillman, W.S. 1956. Injury of tomato plants by continuous light and unfavorable photoperiodic cycles. Amer. J. Bot. 43:89-96.

Hopkins, W.G. 1995. Introduction to plant physiology. Wiley, New York.

Hurd, R.G. 1973. Long-day effects on growth and flower initiation of tomato plants in low light. Ann. Appl. Biol. 73:221-228.

Ibrahim, C.A., A. Lecharny, and B. Millet. 1981. Circadian endogenous growth rhythm in tomato. Plant Physiol. 67(Suppl. 636):113.

Ketellapper, H.J. 1960. Interaction of endogenous and environmental periods in plant growth. Plant Physiol. 35:238-241.

Kozai, T., C. Chun, and K. Ohyama. 2004. Closed systems with lamps for commercial production of transplants using minimal resources. Acta Hort. 630:239-254.

Mancinelli, A.L. 1994. The physiology of phytochromeaction. p. 211-269. In: R.E. Kendrick and G.H.M. Kronenberg(eds.). Photomorphogenesis in plants. 2nd ed. Kluwer Academic Publishers, Dordrecht.

Mohr, H. 1972. Lectures on photomorphogenesis. Springer-Verlag, Berlin.

Morgan, D.C. and H. Smith 1979. A systematic relationship between phytochrome-controlled development and species habitat, for plants grown in simulated natural radiation. Planta 145:253-258.

Oelze-Karow, H. and H. Mohr. 1989. An analysis of phytochrome-mediated threshold control of hypocotyl growth in mustard (Sinapis alba L.) seedlings. Photochem. Photobiol. 50:133-141.

Sailsbury, F.B. and C.W. Ross. 1992. Plant physiology. 4th ed. Wadsworth Publishing, Belmont, Calif.

Taiz, L. and E. Zeiger. 1991. Plant physiology. Benjamin/Cummings Publ., Redwood City, Calif.

Toida, H., Y. Omura, and T. Kozail. 2003a. Growth and development of tomato seedlings under nonperiodic alternation of light and dark periods (In Japanese text with English summary). Environ. Control Biol. 41(2):141-147.

Toida, H., Y. Omura, C. Kubota, and T. Kozai. 2003 b. Growth and development of tomato seedlings under constant light-dark period with random light periods (In Japanese text with English summary). Environ. Control Biol. 41(4):369-375.

Wittwer, S.H. 1963. Photoperiod and flowering in the tomato (Lycopersicon esculentum Mill.). Proc. Amer. Soc. Hort. Sci. 83:688-649. 